\title{
VCUG and the recurring question of sedation: preparation and catheterization technique are the key
}

\author{
D. Gregory Bates
}

Received: 2 December 2011 / Accepted: 5 December 2011 /Published online: 30 December 2011

(C) Springer-Verlag 2011

The voiding cystourethrogram (VCUG) is the most frequently performed fluoroscopic examination in pediatric radiology departments for the investigation of the lower urogenital tract in children. A variety of clinical indications exists and include urinary tract infections (UTI), vesico-ureteral reflux (VUR), prenatal hydronephrosis, congenital renal anomalies, posterior urethral valves (PUV), bladder diverticula, hypospadias, cloacal abnormalities, Mullerian duct remnants, imperforate anus, bladder and urethral trauma, hematuria, urolithiasis, renal transplantation and assessment of the unstable bladder [1-3]. The VCUG is not likely to be replaced any time soon. If one only considers vesicoureteral reflux, an estimated 50,000 children are diagnosed with VUR after urinary tract infection each year in the United States [4]. The number of children undergoing screening examinations, therefore, is likely in the many hundreds of thousands.

The VCUG examination requires transurethral catheterization (excluding suprapubic puncture), instillation of contrast agent for bladder filling, and voiding under direct fluoroscopic imaging. Optimal evaluation includes an awake and cooperative child, limited and optimized image acquisition utilizing last-image-hold techniques and pulsed digital fluoroscopy units, minimal radiation burden and a short examination time $[1,5]$. The vast majority of VCUG examinations are performed primarily on an outpatient basis, unfortunately often with little or no preparation of the child or parent [6]. The VCUG examination can therefore be perceived as a painful

Related articles can be found at doi:10.1007/s00247-011-2322-x and doi:10.1007/s00247-011-2323-9).

D. G. Bates $(\bowtie)$

Department of Radiology, Nationwide Children's Hospital,

700 Children's Drive,

Columbus, OH 43205, USA

e-mail: greg.bates@nationwidechildrens.org investigation associated with high levels of distress and anxiety for the child, parents and even the medical staff [1, 6-14]. The VCUG experience has been described by one author as follows:

"The child may be separated from his or her parents; his or her legs and genitalia are spread apart, often forcibly; probing and intruding into a "private" area not usually touched by strangers; firm pressure may be used to clean the genitalia; a urinary catheter is inserted; and the child must tolerate the discomfort of an unusually full bladder and the indignity of voiding in public. As the child lies flat and still, cold and exposed, huge cameras approach within inches of his or her body and rotate around it" [6].

If this description of the VCUG is the perception of the lay public, then it is not surprising that an uninformed parent would desire, if not demand, that their child be sedated, preferably with general anesthesia. This misunderstanding is certainly doing our families and patients a great disservice. Unfortunately, many children have been irreparably traumatized by previous catheterizations as well as other invasive medical procedures and the mere thought of undergoing an unknown or repeat procedure is unbearable. I believe the use of sedation is entirely appropriate in these patients. As a pediatric radiologist, it is my job to provide the safest, most productive and least distressing examination possible. In my opinion, however, if thorough pre-test preparation of the parent and child were combined with appropriate catheterization techniques, the VCUG examination could be performed without the need for sedation in the vast majority of patients.

The first component of this discussion revolves around patient education. The VCUG examination process actually begins in the ordering physician's office. First and foremost, the physician needs to communicate to the family the reason for the examination, its medical importance to the health of 
the child, and what to expect during the procedure. This seems like such an obvious point, yet any radiologist who performs VCUG examinations has on occasion walked into the fluoroscopy suite only to find a shocked, distraught or even angry parent who had no idea that their child was to undergo this type of an examination. The test is either cancelled, requiring the radiologist to call the referring clinician and explain why the test was not performed, or the examination proceeds in an uncomfortable environment, more often than not resulting in a traumatic experience for the child and parent. This is an unfortunate collapse in the medical system, when there is a wealth of information that can be provided to families and physicians on non-pharmacological preparatory interventions that are simple, reliable and proven techniques. These have been shown to significantly reduce the stress and anxiety level of both the parent and child when invasive testing is ordered [10,15-27]. We, as health care providers, need to be more aggressive in our approach and take the responsibility for preprocedural education. When children and parents are well prepared and familiarized with the procedure, the majority of children will have little or no difficulty with catheterization [10].

So what do we know about children and the VCUG? We know that pre-test therapeutic intervention significantly reduces children's distress [1,9-11] and helps to dispel any preconceived misconceptions associated with the VCUG examination [24]. Unexpected stress is more anxiety-provoking and difficult to deal with than anticipated or predictable stress [1]. Distress levels in children significantly increase during VCUG examinations when parents are reluctant to explain the procedure to their children and omit perceived upsetting details. Parents need to be strongly encouraged to openly discuss all components of the examination with their children, despite their apprehension [9], and parents should be provided with a thorough description of the VCUG examination and how to appropriately communicate that information to the child [10]. We know that the child's age, coping style, previous experiences and quality of parental support all have an impact on the child's reaction to distressing medical investigations. Younger children display more distress and are unable to devise their own cognitive coping strategies. They are dependent on their parents to cope with fear and pain, whereas older children are more adept at mounting independent coping mechanisms $[1,9,26]$. Children who receive both procedural information before the VCUG and distraction techniques during the procedure manifest significantly less demonstrative distress during the examination (e.g., crying and screaming, expressing resistance) [28]. Furthermore, high-level anxiety-linked behaviors following the VCUG examination are reduced to a minimum or even eliminated with these types of interventions [9]. We know that parents need pre-procedural instruction on what their role will be during the examination, and how their interactions will impact the child's behavior during the examination.
Detrimental parental verbal communication during the examination needs to be modified in order to promote appropriate behavior coping skills in their children. Commands to using coping, inappropriate reassurance, apology, empathy, criticism and giving control to the child by adults all promote child distress behavior during medical procedures. The only adult behavior that has been proved to have beneficial results with both child coping and distress are distraction techniques [26, 29]. If we utilized all this information correctly, we would greatly facilitate the performance of the VCUG examination and engender a more positive experience for all our families.

So what options are available to minimize pre-procedural stress and anxiety and optimize compliance during the VCUG examination? This process should begin the instant the examination is scheduled. An appointment letter should be generated and sent to the parents, describing the details of the VCUG procedure from start to finish and a phone number to call should the parents have questions or concerns before or after the examination [10]. This letter can be as simple as a "helping hands" or be a more extensive pamphlet or story booklet that conveys procedural information through the account of one child's experience during the VCUG. The format should include coping strategies that can be adopted by the parents and child at appropriate stages during the VCUG $[9,30]$. This letter might provide a link to a website at the institution, where an instructional video can be watched by the parent and child together detailing the procedural steps from initial arrival to subsequent departure from the radiology department, including a complete tour of the fluoroscopy suite. The most complete preparation for families would be to develop a multidisciplinary team with the addition of certified child life specialists (CCLS). The CCLS has experience in child development, education and psychosocial care of children and families receiving medical care. Pre-procedural telephone consultation would be provided 7-10 days in advance of the procedure and designed to provide individual guidance to parents to assist in developing a plan that suits each child's unique personality. This would provide an opportunity for families to practice coping strategies at home with their children, promoting more effective interaction prior to and during the procedure [27]. On the day of the examination, the CCLS would provide age-appropriate developmental interventions and play utilizing a vast array of coping supplies, particularly designed around regulating breathing, stress relief and diversion. These might include bubbles, pinwheels and party blowers for the younger children. Stress relievers are any item that allows children to divert muscle activity to another part of the body during the examination, i.e. Playdough. Diversional schemes include stickers, pop-up books, music, cartoons, movies, cause/effect toys, electronic games, MP3 players and interactive games. Incorporation of image viewing systems (i.e. video goggles) from MRI has also been suggested 
[31]. Personal items from home should be incorporated with the visit if there is a preference. The CCLS would continually assess the child's comfort level and reaction to the procedure and respond appropriately [23, 32].

The second component of the discussion regarding the need for sedation during the VCUG revolves around the perception of pain and urethral catheterization. The three major reasons I believe this procedure can be performed in an essentially painless fashion are as follows:

1. In my experience, the older child who can verbally communicate his or her discomfort during the procedure is many times unaware that catheterization has taken place if distracted with non-procedural conversation between myself, a technician or parent. There is no reason to suspect that an infant or younger child should feel any significant discomfort using the same technique.

2. It is my observation that for any child who appears to exhibit pain during catheterization, there is a child of identical age and gender that can be catheterized under the same conditions without appearing to experience pain. The act of catheterization itself therefore, is likely not the causative factor.

3. The use of daily (range $2-8$ catheterizations per day) clean intermittent catheterization (CIC) in the management of dysfunctional voiding associated with a large postresidual (non-neurogenic voiding dysfunction) is performed in children who are neurologically and anatomically normal (genitally sensate children) [33-35]. CIC is a simple technique for parents and children to master, with high long-term success rates, and is associated with a high recorded level of comfort.

There are three relatively invasive aspects of urethral catheterization perceived by children: the washing of the perineum, the installation of anesthetic jelly, and the insertion of the catheter [29]. Particular attention to each component promotes greater success with each subsequent step and helps to significantly reduce or alleviate any discomfort during this procedure. It is my opinion as well as others' [36-39] that the liberal use of an injectable 2\% lidocaine gel (Uro-Jet, International Medication Systems Limited, El Monte, CA, USA) is effective for catheterization in all patients and plays a significant role in reducing any discomfort. Lidocaine gel has an onset of action of 1-4 min and lasts 12-45 $\mathrm{min}$ [37]. The cost and time added to the study are minimal and there are no reports of adverse side effects with lidocaine lubricant for catheterization in children [38]. When performed with care and appropriate technique, the catheterization of a child can be achieved without any significant distress.

In the female, lidocaine gel is liberally placed over the urethral meatus and adjacent tissues and covered with a sterile cotton ball for 2-3 min prior to cleansing of the genitalia and catheterization. The urethral meatus should be clearly identified before attempting catheterization. Ensure there is adequate lighting. If the urethral orifice is not clearly seen, distracting the labia in an upward and outward fashion will help. Repetitive poking and prodding with the catheter tip is unnecessary and discouraged. In the male, the urethral meatus is initially coated with lidocaine gel for 2-3 min after cleansing. The urethral meatus is then injected with enough lidocaine gel to ensure filling of the entire urethra. This generally requires $1-2 \mathrm{ml}$ in the newborn and up to $10 \mathrm{ml}$ in the older adolescent [36]. The tip of the penis is gently squeezed to prevent loss of gel at the meatus for a minimum of $3 \mathrm{~min}$. The catheter is then gently advanced through the urethra and into the bladder, utilizing the geldistended urethra. If resistance is encountered at the external sphincter, ask the older child to either exhale or to try to "pee." This generally relaxes the sphincter for an instant, allowing advancement. In the younger child, dripping warm water over the perineum almost always relaxes the sphincter.

Recent attention has been focused, and rightly so, on the issue of pediatric pain management and procedural sedation for children undergoing invasive procedures. Pain and distress experienced by children during medical procedures increases distress and anxiety during subsequent procedures. Because many children with urological abnormalities require testing at regular intervals, it is particularly important to use strategies that minimize distress and discomfort [38, 40]. There is no doubt that pharmacological intervention not only provides sedation but also includes analgesic, anxiolytic and amnesic effects. Sedation, however, brings with it cost, time and safety concerns [13]. While generally safe, these drugs can induce cardiovascular depression, hypoxia, apnea, unconsciousness and rarely death, even in dosages well tolerated [19]. I will agree that the use of sedation for the VCUG examination is beneficial in select cases, but a blanket statement that all or the large majority of children need sedation for this procedure is simply not true and diminishes the importance of the skill and expertise of the pediatric radiologist and the availability of a variety of non-pharmacological interventions.

A pro-active approach appears to be the most beneficial method to ensure a complete and non-stressful VCUG examination in children. Pre-procedural preparation, with a structured program promoting the use of active coping strategies, significantly reduces the likelihood of any emotional trauma [14]. Discussing the procedure with the child and parent and soliciting their opinions not only conveys respect but also results in greater cooperation to achieve the goal [32]. Children who are psychologically prepared for the examination will recover faster and with less emotional distress. Parents are reassured by knowing what to expect during their visit and by the knowledge that urinary catheterization of children is routine in a pediatric imaging department. An approach that provides comfort and eliminates the need 
for pharmacological intervention is, therefore, the most desirable intervention [19].

Food for thought: I find it quite interesting that there is such great consternation over the VCUG examination, yet there is no similar outcry for universal sedation of children who are routinely catheterized in pediatrician and urologist offices, the emergency room and on inpatient units on a daily basis. If there were a universal mandate on how to appropriately catheterize children in a nearly painless fashion, then this argument would be moot. However, if the argument is that sedation is primarily needed to prevent the stress and anxiety associated with invasive medical procedures in children, then how can we justify not routinely sedating for immunizations, blood draws, naso-enteric tube placement, lumbar punctures, barium enemas etc.? These procedures surely are equally as distressing to children. Just a thought.

\section{References}

1. Agrawalla S, Pearce R, Goodman TR (2004) How to perform the perfect voiding cystourethrogram. Pediatr Radiol 34:114-119

2. Schneider K, Krüger-Stollfuss I, Ernst G et al (2001) Paediatric fluoroscopy - a survey of children's hospitals in Europe. I. Staffing, frequency of fluoroscopic procedures and investigation technique. Pediatr Radiol 31:238-246

3. Mussurakis S, Sprigg A, Steiner GM (1994) The appropriateness of use and the clinical impact of micturating cystourethrography in paediatric practice. Clin Radiol 49:541-545

4. Elder JS (2005) Imaging for vesicoureteral reflux-is there a better way? J Urol 174:7-8

5. Riccabona M (2002) Cystography in infants and children: a critical appraisal of the many forms with special regard to voiding cystourethrography. Eur Radiol 12:2910-2918

6. Stashinko EE, Goldberger J (1998) Test or trauma? The voiding cystourethrogram experience of young children. Issues Compr Pediatr Nurs 21:85-96

7. Srivastava T, Betts G, Rosenberg AR et al (2001) Perception of fear, distress and pain by parents of children undergoing a micturating cystourethrogram: a prospective study. J Paediatr Child Health 37:271-273

8. Merritt KA, Ornstein PA, Spicker B (1994) Children's memory for a salient medical procedure: implications for testimony. Pediatrics 94:17-23

9. Phillips DA, Watson AR, MacKinlay D (1998) Distress and the micturating cystourethrogram: does preparation help? Acta Paediatr 87:175-179

10. Zelikovsky N, Rodrigue JR, Gidycz CA et al (2000) Cognitive behavioral and behavioral interventions help young children cope during a voiding cystourethrogram. J Pediatr Psychol 25:535-543

11. Salmon K, Pereira JK (2002) Predicting children's response to an invasive medical investigation: the influence of effortful control and parent behavior. J Pediatr Psychol 27:227-233

12. Robinson M, Savage J, Stewart M et al (1999) The diagnostic value, parental and patient acceptability of micturating cysto-urethrography in children. Ir Med J 92:366-368

13. Herd DW (2008) Anxiety in children undergoing VCUG: sedation or no sedation? Adv Urol. doi:10.1155/2008/498614

14. Phillips D, Watson AR, Collier J (1996) Distress and radiological investigations of the urinary tract in children. Eur J Pediatr 155: 684-687
15. Gladh G (2003) Effect of thoughtful preparation on the catheterization of children undergoing investigative studies. Neurourol Urodyn 22:58-61

16. Blount RL, Powers SW, Cotter MW et al (1994) Making the system work. Training pediatric oncology patients to cope and their parents to coach them during BMA/LP procedures. Behav Modif 18:6-31

17. Campbell L, Clark M, Kirkpatrick SE (1986) Stress management training for parents and their children undergoing cardiac catheterization. Am J Orthopsychiatry 56:234-243

18. Manne SL, Redd WH, Jacobsen PB et al (1990) Behavioral intervention to reduce child and parent distress during venipuncture. $\mathrm{J}$ Consult Clin Psychol 58:565-572

19. Lang EV, Benotsch EG, Fick LJ et al (2000) Adjunctive nonpharmacological analgesia for invasive medical procedures: a randomised trial. Lancet 355:1486-1490

20. Fick LJ, Lang EV, Logan HL et al (1999) Imagery content during nonpharmacologic analgesia in the procedure suite: where your patients would rather be. Acad Radiol 6:457-463

21. Peterson L, Shigetomi C (1981) The use of coping techniques to minimise anxiety in hospitalized children. Behaviour Therapy 12:1-14

22. Goldberger J, Gaynard L, Wolfer J (1990) Helping children cope with health-care procedures. Contemp Pediatr 7:141-163

23. McGee K (2003) The role of a child life specialist in a pediatric radiology department. Pediatr Radiol 33:467-474

24. Chesson RA, Good M, Hart CL (2002) Will it hurt? Patients' experience of X-ray examinations: a pilot study. Pediatr Radiol 32:67-73

25. Brewer S, Gleditsch SL, Syblik D et al (2006) Pediatric anxiety: child life intervention in day surgery. J Pediatr Nurs 21:13-22

26. Blount RL, Landolf-Fritsche B, Powers SW et al (1991) Differences between high and low coping children and between parent and staff behaviors during painful medical procedures. J Pediatr Psychol 16:795-809

27. Butler LD, Symons BK, Henderson SL et al (2005) Hypnosis reduces distress and duration of an invasive medical procedure for children. Pediatrics 115:e77-85

28. Salmon K, McGuigan F, Pereira JK (2006) Brief report: optimizing children's memory and management of an invasive medical procedure: the influence of procedural narration and distraction. Pediatr Psychol 31:522-527

29. Kleiber C, McCarthy AM (1999) Parent behavior and child distress during urethral catheterization. J Soc Pediatr Nurs 4:95-104

30. Children's Renal \& Urology Unit (2007) Micturating cystourethrogram. Sharon/Darren has a very important test. NKF Controlled Document No. 114. Nottingham University Hospital, Nottingham, UK. Available via http://www.kidney.org.uk/kids/mict_cyst/mict_cyst. html. Accessed 05 Dec 2011

31. Koch BL (2008) Avoiding sedation in pediatric radiology. Pediatr Radiol 38(Suppl 2):S225-S226

32. Stephens BK, Barkey ME, Hall HR (1999) Techniques to comfort children during stressful procedures. Accid Emerg Nurs 7:226-236

33. Pohl HG, Bauer SB, Borer JG et al (2002) The outcome of voiding dysfunction managed with clean intermittent catheterization in neurologically and anatomically normal children. BJU Int 89: 923-927

34. Alpert SA, Cheng EY, Zebold KF et al (2005) Clean intermittent catheterization in genitally sensate children: patient experience and health related quality of life. J Urol 174(4 Pt 2):1616-1619, discussion 1619

35. Van Savage JG, Sackett CK, Wilhelm CL et al (1997) Indications for and outcomes of clean intermittent catheterization in children with normal genital sensation. J Urol 157:1866-1868

36. Gray M (1996) Atraumatic urethral catheterization of children. Pediatr Nurs 22:306-310 
37. Siderias J, Guadio F, Singer AJ (2004) Comparison of topical anesthetics and lubricants prior to urethral catheterization in males: a randomized controlled trial. Acad Emerg Med 11:703-706

38. Gerard LL, Cooper CS, Duethman KS et al (2003) Effectiveness of lidocaine lubricant for discomfort during pediatric urethral catheterization. J Urol 170(2 Pt 1):564-567
39. Mularoni PP, Cohen LL, DeGuzman M et al (2009) A randomized clinical trial of lidocaine gel for reducing infant distress during urethral catheterization. Pediatr Emerg Care 25:439-443

40. Zier JL, Drake GJ, McCormick PC et al (2007) Case-series of nurse-administered nitrous oxide for urinary catheterization in children. Anesth Analg 104:876-879 